Colonization success of carabid beetles on Baltic islands

Kotze, D.J.

Blackwell

2000

Kotze, D.J., Niemelä, J. and Nieminen, M. 2000. Colonization success of carabid beetles on Baltic islands. Journal of Biogeography 27: 807-819.

http://hdl.handle.net/1975/312

Downloaded from Helda, University of Helsinki institutional repository.

This is an electronic reprint of the original article.

This reprint may differ from the original in pagination and typographic detail.

Please cite the original version. 


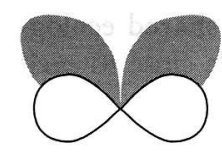

\title{
Colonization success of carabid beetles on Baltic islands
}

D. Johan Kotze, Jari Niemelä and Marko Nieminen Department of Ecology and Systematics, Division of Population Biology, PO Box 17 (Arkadiankatu 7), FIN-00014, University of

Helsinki, Finland

\begin{abstract}
Aims (1) To test whether there is a significant increase in carabid species richness with an increase in island size and, if so, if it is due to island area per se or habitat diversity. (2) To investigate whether scattered islands accumulate species quicker than islands close to each other, per island size. (3) To investigate changes in the proportions of carabid wing morphs between the Finnish mainland and islands in the Baltic Sea.
\end{abstract}

Location Islands in the south-western archipelago of Finland, in the Baltic Sea.

Methods Carabid beetles were collected using pitfall traps (diameter, $65 \mathrm{~mm}$; volume, $170 \mathrm{~mL}$ ), half-filled with an ethylene-glycol-water mixture, from 22 May to 20 September 1993 on 24 islands. Island size varied between 0.5 and $c .7000$ ha, and each island had between one and four habitat types sampled.

Results A total of 61 carabid species were captured on these islands. Pterostichus niger was numerically dominant on 15 of the 24 islands and made up $34.5 \%$ of the total catch. The islands had a significantly higher proportion of brachypterous species compared to the Finnish mainland. The islands also accumulated species at a much slower rate $(z=0.06)$ than that generally observed in the literature, and, for carabids, a mainly predacious group, habitat diversity had little predictive power in explaining species richness. Islands close to each other (a few hundred metres apart) accumulated species at a slower rate than did scattered islands, as island size increased.

Main conclusions Although carabids disperse relatively easily to remote islands (perhaps a result of low Baltic Sea salinity and short interisland distances), colonization success appears to depend on a multitude of factors, including availability of suitable habitat on these islands, competitive superiority, survival ability during dispersal and island arrival sequence.

\section{Keywords}

Baltic Sea, Carabidae, habitat diversity, island theory, metapopulation dynamics.

\section{INTRODUCTION}

The observation that larger areas have more species than smaller ones is one of the most well-studied generalizations in ecology today (MacArthur \& Wilson, 1967; Rosenzweig, 1995; Wu \& Vankat, 1995). Three basic, not mutually exclusive, concepts explain this species-area relationship (MacArthur \& Wilson, 1967; Ås et al., 1997). First, there is an increase in the total number of individuals with increasing area and, as there usually is a positive relationship between the number of individuals and the number of species, larger areas will have

Correspondence: D. Johan Kotze, Department of Ecology and Systematics, Division of Population Biology, PO Box 17 (Arkadiankatu 7), FIN-00014, University of Helsinki, Finland. E-mail: johan.kotze@helsinki.fi more species than smaller ones. Second, larger areas have more habitats and/or niches, with a corresponding increase in species richness. Third, colonization-extinction dynamics predict that there will be more species in larger areas than in smaller ones (MacArthur \& Wilson's 1967 original idea). However, there is still considerable debate on which mechanism is most appropriate in explaining species-area relationships. For example, many case studies on Baltic Sea islands show that, although habitat diversity might be important, a significant increase in species number with area per se exists (Ås et al., 1997).

Finnish and Swedish coasts along the brackish Baltic Sea are rich in islands, with the Stockholm archipelago alone, for example, consisting of c. 30,000 islands (Ås et al., 1997). Islands off the Scandinavian Peninsula are of considerable theoretical, biological and conservation importance, and are 
among the best studied in the world (Järvinen \& Ranta, 1987). Theoretically, these islands have fascinated scientists examining species richness (e.g. Niemelä et al., 1985, 1986, 1987; Järvinen \& Ranta, 1987; Niemelä, 1988a,b) and metapopulation dynamics (e.g. Nieminen \& Hanski, 1998; Saccheri et al., 1998; Hanski, 1999). In terms of conservation, these islands are of particular interest as they contain habitat types not typically found on the mainland, and species occurring on islands are more susceptible to extinction than their mainland counterparts (Ås et al., 1997).

Life is quite a young phenomenon on these islands, a result of both their recent emergence after the last glaciation between 15,000 and 8000 years ago and the fact that the islands are still rising out of the Baltic Sea (Ås et al., 1997). Baltic islands are also of particular interest as they differ from oceanic islands in two important ways: (1) salinity is low (see Ås, 1984) and increases occasionally with the inflow of salt water from the North Sea between Denmark and Sweden; and (2) because of the high island richness off the Finnish and Swedish coasts, interisland distances are generally short. In fact, Järvinen \& Ranta (1987) argue that, for most taxa, island colonization is easy because of the short interisland distances, but persistence might be more difficult due to a lack of suitable habitat or the presence of a harsh climate.

Consequently, it is unclear whether dispersal (measured as active, i.e. directed flight, or passive, i.e. wind, rafting or floating) or actual colonization ability (suitable habitat and competitive superiority) is important in the observed incidences of species on these islands (Niemelä, 1992). For example, are islands sufficiently close to each other, and to the mainland (a significant rescue effect), so that dispersal features (i.e. functional wings) are unimportant in explaining incidence (Ås, 1984)? If so, what effect does this have on the speciesarea relationship, and how important is habitat diversity or the occurrence of suitable habitat on these islands?

Carabid beetles (Coleoptera: Carabidae) provide an excellent opportunity to study island theory in the Baltic Sea for a number of reasons. First, the group is both ecologically and behaviourally well known, which makes ecological studies possible. Second, carabid species can be classified into dispersal types by wing morphism (but see Ås, 1984). Third, previous studies have shown that carabids occur in abundance on these islands and are easily sampled using standard techniques (Lindroth, 1985, 1986; Niemelä, 1992, 1996).

In this study, the following questions were asked. (1) Is there a significant increase in carabid species richness as island size increases and, if so, is this due to island area per se or to habitat variety? (2) Do scattered islands accumulate species quicker than islands close to each other, per size, as predicted by Hanski \& Gyllenberg (1997)? If we assume between-island colonization for islands close to each other, but mainly mainland colonization of scattered islands, the former islands may accumulate species at a slower rate because they 'compete' for immigrants (Nieminen \& Hanski, 1998). (3) Can carabid wing morphism explain species incidence on islands in the Baltic Sea? For example, are there differences in the proportions of winged and wingless species between mainland Finland and the islands and between group and scattered islands? (4) Are there shared ecological characteristics of species found on islands close to each other or scattered islands?

\section{MATERIALS AND METHODS}

\section{Study area and carabid sampling}

Twenty-four islands were sampled off the south-western coast of Finland (Fig. 1), in the hemiboreal vegetation zone (Esseen et al., 1997). Island size ranged from 0.5 to $c .7000$ ha, and islands were divided into: (1) three large islands; (2) two island groups of seven islands each (an eastern and western group); and (3) seven scattered islands (Table 1). Islands in the eastern and western groups were in close proximity to each other (maximally a few hundred metres apart), while islands in the scattered group were remote (several kilometres apart). Scattered islands all had unstudied islands nearby, but these were mainly small and consisted mostly of bare rock (Fig. 1).

Thirteen different habitat types were sampled, including mixed deciduous forest, mixed alder and spruce forest, alder, aspen, birch, pine and spruce forest, scrub (a dry heathlandlike habitat with juniper bushes and Calluna vulgaris (L.) Hull 1808 (heather)), bogs, shore meadows and three types of fields (see Fig. 3). Islands ranged from having a maximum of four habitat types sampled to a minimum of one (Table 1). Not all habitat types present on these islands were sampled, and larger islands, in particular, were undersampled.

Carabid beetles were collected using pitfall traps (diameter, $65 \mathrm{~mm}$; volume, $170 \mathrm{~mL}$ ), half-filled with an ethylene-glycolwater mixture. Roofs were placed above the traps to prevent liquid dilution and trap overflow from rain. Pitfall trapping is an efficient technique for capturing epigaeic invertebrates. It is, however, by no means an exhaustive method, and rare and less active species are probably undersampled (Spence \& Niemelä, 1994). Six traps were placed in a row $5 \mathrm{~m}$ apart per habitat type, giving a total of 366 pitfall traps placed on the islands. As six traps were used per habitat type, the total number of traps per island varied from six to 24 , whereas island size varied between 0.5 and c. 7000 ha. Consequently, larger islands are likely to be undersampled and this is considered in the interpretation of the results.

Trapping started on 22 May 1993 and traps were visited twice a month until 20 September 1993. Beetles were identified to species level and their nomenclatural authorities are given in the Appendix.

\section{Statistical analyses}

In comparing species richness among the 24 islands, and among mixed forest and scrub habitats separately (these were the two most commonly found habitat types on the islands), we adjusted the species richness data to compensate for varying sample sizes. This was done by rarefaction, a statistical procedure for estimating the number of species expected in a random subsample drawn from a larger sample (Simberloff, 1978; Magurran, 1988), using BIODIV software (Baev \& Penev, 1995). Species-area plots were constructed in log-log 
Figure I Map of the study area in the south-western archipelago of Finland. Shaded islands represent the study islands. Group islands are encircled. Numbers next to the islands correspond to the island names in Table 1.

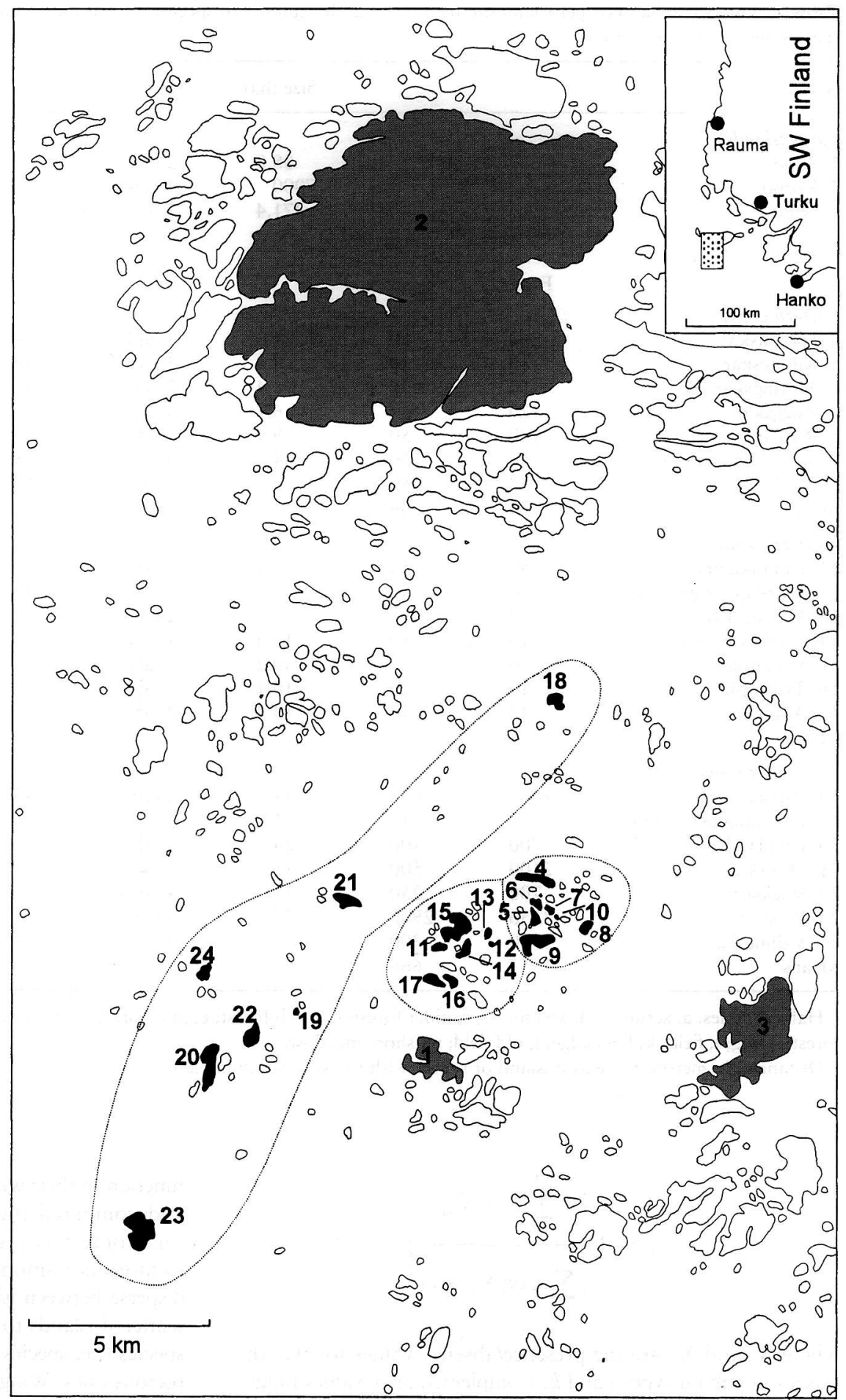

diversity plot, a species-island size plot comparing only mixed forest and one comparing only scrub habitat.

Habitat distinctness in carabid assemblages was examined using both cluster analysis (Bray-Curtis similarity percentage) and paired complementarity calculations. Complementarity was calculated using the formula: 
Table I Number of habitats per island sampled $(H)$ and the number of species $(S)$ and individuals $(I)$ captured per island. The most abundant species per island is also given.

\begin{tabular}{|c|c|c|c|c|c|c|c|}
\hline Island & & & Size (ha) & $H^{*}$ & $S$ & $I$ & Most abundant species (\%) \\
\hline \multicolumn{8}{|l|}{ Large islands } \\
\hline 1. Aspö & & & 88.8 & $2(b c)$ & 17 & 1230 & Pterostichus niger (25.6) \\
\hline 2. Korpo & & & 7000 & $4($ ackl) & 26 & 663 & Agonum fuliginosum (26.7) \\
\hline \multirow[t]{3}{*}{ 3. Nötö } & \multirow{2}{*}{\multicolumn{2}{|c|}{ Distance $(\mathrm{m}) \dagger$}} & 371.4 & $2(\mathrm{ej})$ & 26 & 566 & Pterostichus niger (29.3) \\
\hline & & & & & & & \\
\hline & Forest & Scrub & & & & & \\
\hline \multicolumn{8}{|l|}{ Eastern group } \\
\hline 4. Håkonskär & 200 & 20 & 23.0 & 4 (abhi) & 24 & 1410 & Agonum fuliginosum (24.1) \\
\hline 5. Killingskär & 50 & 10 & 8.4 & $2(\mathrm{ad})$ & 14 & 621 & Calathus micropterus (36.9) \\
\hline 6. Moringskär (east) & 50 & 50 & 5.4 & $2(\mathrm{ad})$ & 12 & 60 & Calathus micropterus (31.7) \\
\hline 7. Ruggskär & 20 & 20 & 6.7 & 3 (ade) & 18 & 968 & Platynus obscurus (36.5) \\
\hline 8. Röskär & 100 & 50 & 9.9 & $2(a b)$ & 19 & 1220 & Pterostichus niger (44.2) \\
\hline 9. Stora Hummelskär & 50 & 50 & 34.7 & $3(\mathrm{abc})$ & 18 & 1300 & Patrobus assimilis (26.5) \\
\hline 10. Y-skerry & 50 & 50 & 0.6 & 1 (a) & 15 & 309 & Pterostichus niger (59.5) \\
\hline Means & 74 & 36 & & & & & \\
\hline \multicolumn{8}{|l|}{ Western group } \\
\hline 11. Lammkläppen & 50 & 50 & 6.2 & $2(\mathrm{af})$ & 10 & 149 & Pterostichus niger (29.5) \\
\hline 12. Moringskär grundet & 150 & 150 & 0.5 & $1(\mathrm{a})$ & 10 & 113 & Carabus hortensis (69.0) \\
\hline 13. Moringskär (west) & 400 & 150 & 3.2 & $2(\mathrm{af})$ & 14 & 152 & Pterostichus niger (34.9) \\
\hline 14. Snäruskär (east) & 10 & 10 & 12.4 & 4 (abce) & 17 & 1080 & Pterostichus niger (52.2) \\
\hline 15. Storlandet & 100 & 20 & 40.2 & $3(a b c)$ & 15 & 1090 & Pterostichus niger (41.3) \\
\hline 16. Tvisingskär & 10 & 10 & 10.1 & $3(\mathrm{abi})$ & 12 & 509 & Agonum fuliginosum (28.7) \\
\hline 17. Ängskär & 10 & 10 & 14.3 & $2(a b)$ & 10 & 165 & Pterostichus niger (62.4) \\
\hline Means & 104 & 57 & & & & & \\
\hline \multicolumn{8}{|l|}{ Scattered group } \\
\hline 18. Barskär & 1800 & 600 & 11.7 & $2(a b)$ & 13 & 117 & Calathus micropterus (30.8) \\
\hline 19. Fränukläppen (south) & 1100 & 10 & 1.1 & 1 (a) & 8 & 122 & Pterostichus niger (38.5) \\
\hline 20. Långlandet & 700 & 100 & 24.1 & $3(\mathrm{abg})$ & 20 & 745 & Pterostichus niger (49.9) \\
\hline 21. Ormskär & 2100 & 500 & 15.6 & $2(a b)$ & 17 & 599 & Pterostichus niger (68.6) \\
\hline 22. Stackskär & 700 & 250 & 16.0 & $4(\mathrm{abcm})$ & 21 & 1650 & Pterostichus niger (43.4) \\
\hline 23. Vidskär & 3750 & 2900 & 57.1 & 4 (abch) & 18 & 835 & Pterostichus niger (48.4) \\
\hline 24. Vällingskär & 1450 & 300 & 9.5 & $3(\mathrm{abc})$ & 18 & 400 & Pterostichus niger (35.3) \\
\hline Means & 1657 & 666 & & & & & \\
\hline
\end{tabular}

* Habitat codes: a, scrub; b, mixed forest; c, alder forest; d, birch forest; e, pine forest; f, spruce forest; $g$, aspen forest; h, alder and spruce forest; i, bog; $j$, field; $k$, field edge; l, old field; $m$, shore meadow.

† Distances, in metres, to nearest island or skerry with forest or scrub habitat.

$$
C_{j k}=100\left(\frac{\sum_{i=1}^{S i k}\left|X_{i j}-X_{i k}\right|}{\sum_{i=1}^{S j k} \max \left(X_{i j}, X_{i k}\right)}\right)
$$

where $X_{i j}$ and $X_{i k}$ are the presence/absence values for the $i$ th species in habitat types $j$ and $k$. Complementarity values range between $100 \%$ (no species shared) and $0 \%$ (identical species lists) (Colwell \& Coddington, 1994).

In addition, we compared species accumulations between group and scattered islands. Recent studies predict shallower slopes for islands with between-island colonization than for islands which are colonized from the mainland only (Hanski \& Gyllenberg, 1997; Nieminen \& Hanski, 1998). Furthermore, we assumed that carabid dispersal ability is a function of their wing development (Niemelä \& Spence, 1999), and compared the proportion of species with long wings (macropterous), short wings (brachypterous) and both (dimorphic) among island groups. If carabids use flight to disperse between islands in this archipelago, we would expect scattered islands to have a higher proportion of macropterous species (i.e. species that have the potential to fly) than brachypterous ones. Wing development is well known for northern European carabids and was taken from the literature (Lindroth, 1985, 1986). However, the risk exists that dimorphic species are only represented by one of the morphs in our material. This is kept in mind when interpreting the results.

Finally, the numbers of occupied scattered islands were compared with the numbers of occupied group islands (eastern and western groups combined), by each species, using Wilcoxon signed-rank tests. Again, carabid dispersal ability 
Figure 2 Species-area and species-habitat diversity relationships. (A) The relationship between $\log$ rarefied number of carabid species captured against log island area and against untransformed habitat diversity. (B) The relationship between log rarefied number of carabid species captured against $\log$ island size where only mixed forest and scrub habitat types were considered.
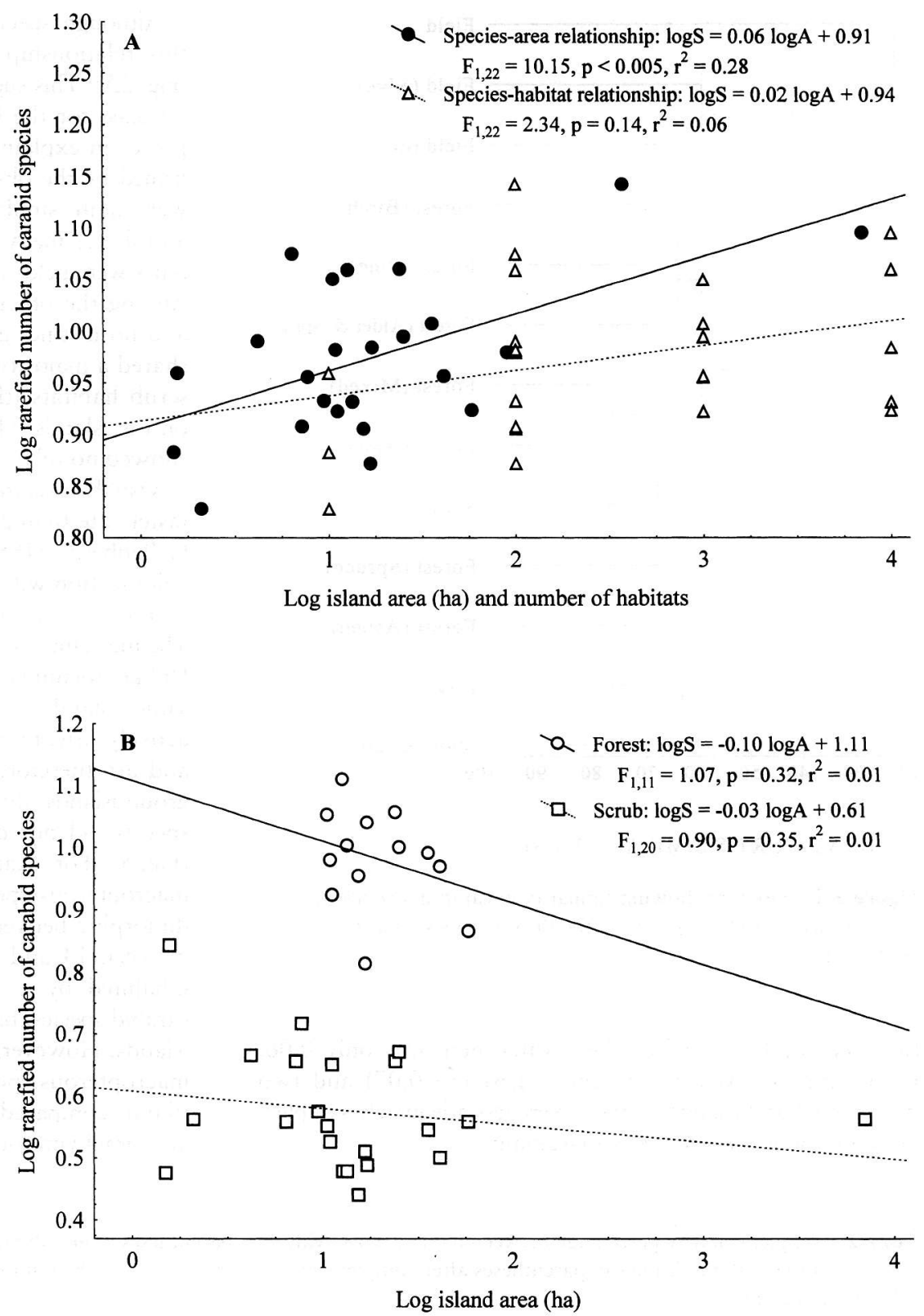

as a function of wing development was used to investigate Nieminen \& Hanski's (1998) prediction that strong fliers (in carabids, long-winged species) can actively orientate their flight to islands from some distance and should therefore be more frequent on scattered than on group islands.

\section{RESULTS}

\section{Dominance and carabid species richness patterns on the islands}

Sixty-one carabid species were captured in 16,073 individuals (Appendix). The 13 most abundant species contributed to over $95 \%$ of total carabid abundance. Pterostichus niger was the most abundant species captured $(34.5 \%$ of the total abundance), close to three times more abundant than the second most abundant species, Agonum fuliginosum (11.8\%). The number of species captured per island and the most abundant carabid species captured on each island are represented in Table 1 . On 15 of the 24 islands $P$. niger was the most abundant species captured, but was not the most abundant species captured on the largest island, Korpo, where A. fuliginosum was most abundant.

Carabid species richness increased significantly with island size (Fig. 2A). Although significant, larger islands did not acquire species at the rate suggested in the literature. Values of $z$ among islands ranged typically between 0.25 and 0.35 (MacArthur \& Wilson, 1967; Järvinen \& Ranta, 1987; 


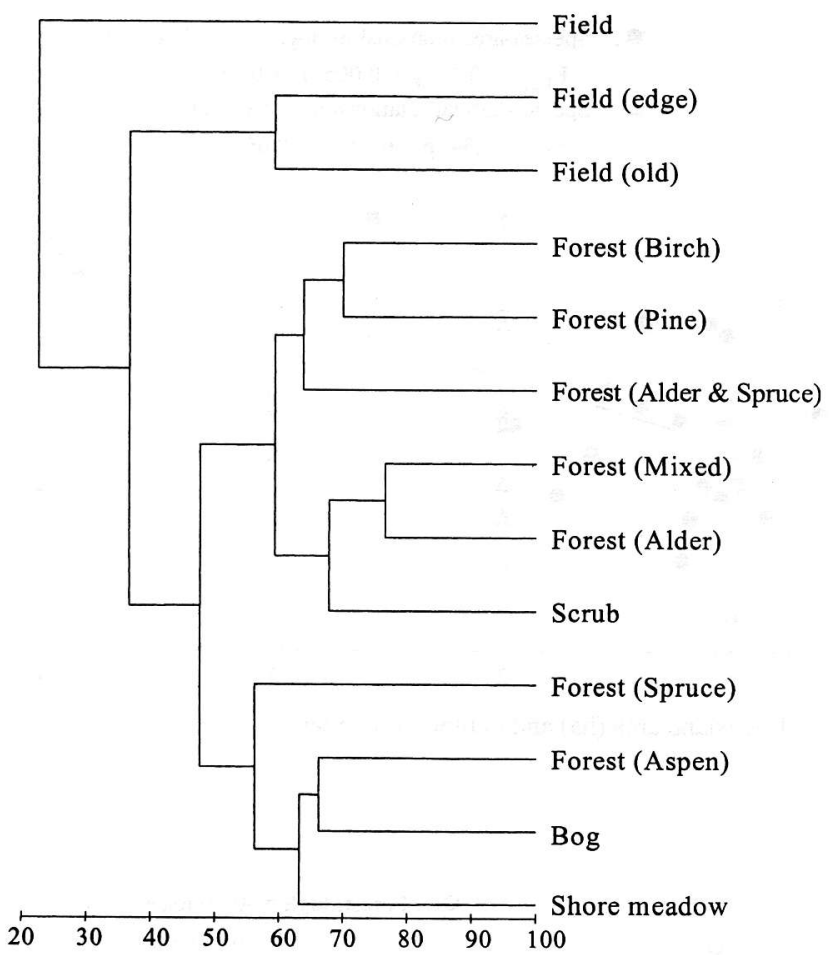

\section{BRAY-CURTIS SIMILARITY (\%)}

Figure 3 Dendogram showing similarity in carabid assemblage structure with habitat type, using the Bray-Curtis similarity percentage index.

Rosenzweig, 1995), while the $z$ value here was only 0.06 . Even with the exclusion of the largest $(z=0.07)$ and two largest $(z=0.04)$ islands, as these were less adequately sampled, the slope value changed only marginally.
Although species richness increased with habitat diversity, this relationship was not significantly different from zero (Fig. 2A). This suggested that habitat diversity on these islands (at least for the habitats sampled here) had little predictive power in explaining carabid species richness. This was confirmed by the observation that many of the habitats sampled were quite similar in carabid assemblage structure (Fig. 3) and shared many species (Table 2). The most dissimilar habitat types were fields found only on the two largest islands (Fig. 3). Among the other habitat types, there was a high similarity and no distinct groupings. Furthermore, most habitat types shared a majority of their species with either mixed forest or scrub habitats (the two most common habitat types found on the islands) (Table 2), but carabids in these habitat types showed no relationship with island size (Fig. 2B).

Visually, scattered islands did accumulate species at a faster rate than group islands (Fig. 4), supporting Hanski \& Gyllenberg's (1997) theory that islands with between-island colonization will have a shallower slope than islands that are mainly colonized from the mainland, i.e. scattered islands. The mechanisms involved in this pattern are, however, unclear. Unlike Nieminen \& Hanski's (1998) study on moths on the same islands, where they suggest that strong fliers can actively orientate their flight to islands from some distance, and are therefore more frequently found on scattered than group islands, the proportion of winged and wingless carabid species did not differ between scattered and group islands (Fig. 5). For example, on islands, the mean proportion of macropterous species ranged between 16 and $23 \%$, that of dimorphic between 12 and $16 \%$ and that of brachypterous between 14 and $15 \%$ (Fig. 5A). The scattered islands were inhabited by a higher mean proportion of macropterous carabid species, but so too were the eastern and western group islands. However, a larger mean proportion of individuals of macropterous species $(7.9 \%)$ was captured on the scattered islands compared to that of individuals of dimorphic $(2.3 \%)$ and brachypterous $(4.1 \%)$ species (Fig. $5 B)$. In contrast, the

Table 2 Complementarity percentage between habitat types. Values in parentheses after habitat names are the total number of carabid species captured in that habitat. Values in parentheses after complementarity percentages are the number of carabid species shared between the two habitat types compared.

\begin{tabular}{|c|c|c|c|c|c|c|c|c|c|c|c|c|}
\hline & $\begin{array}{l}\text { Forest: } \\
\text { Mixed } \\
(32)\end{array}$ & $\begin{array}{l}\text { Forest: } \\
\text { Alder } \\
(31)\end{array}$ & $\begin{array}{l}\text { Forest: } \\
\text { Birch } \\
(19)\end{array}$ & $\begin{array}{l}\text { Forest: } \\
\text { Pine } \\
(16)\end{array}$ & $\begin{array}{l}\text { Forest: } \\
\text { Spruce } \\
(8)\end{array}$ & $\begin{array}{l}\text { Forest: } \\
\text { Al \& Spr } \\
(15)\end{array}$ & $\begin{array}{l}\text { Forest: } \\
\text { Aspen } \\
(13)\end{array}$ & $\begin{array}{l}\text { Scrub } \\
(33)\end{array}$ & $\begin{array}{l}\text { Bog } \\
(10)\end{array}$ & $\begin{array}{l}\text { Field: } \\
\text { edge } \\
(8)\end{array}$ & $\begin{array}{l}\text { Field: } \\
\text { old } \\
(16)\end{array}$ & $\begin{array}{l}\text { Field } \\
\text { (18) }\end{array}$ \\
\hline Forest: Alder (31) & $38(24)$ & - & & & & & & & & & & \\
\hline Forest: Birch (19) & $54(16)$ & $57(15)$ & - & & & & & & & & & \\
\hline Forest: Pine (16) & $59(14)$ & $58(14)$ & $48(12)$ & - & & & & & & & & \\
\hline Forest: Spruce (8) & $75(8)$ & $74(8)$ & $58(8)$ & $50(8)$ & - & & & & & & & \\
\hline Forest: Al \& Spr (15) & $58(14)$ & $52(15)$ & $52(11)$ & $52(10)$ & $56(7)$ & - & & & & & & \\
\hline Forest: Aspen (13) & $59(13)$ & $67(11)$ & $61(9)$ & $47(10)$ & $50(7)$ & $60(8)$ & - & & & & & \\
\hline Scrub (33) & $49(22)$ & $48(22)$ & $51(17)$ & $60(14)$ & $76(8)$ & $59(14)$ & $69(11)$ & - & & & & \\
\hline $\operatorname{Bog}(10)$ & $69(10)$ & $68(10)$ & $68(7)$ & $56(8)$ & $36(7)$ & $53(8)$ & $36(9)$ & $74(9)$ & - & & & \\
\hline Field: edge (8) & $82(6)$ & $74(8)$ & $71(6)$ & $67(6)$ & $55(5)$ & $65(6)$ & $69(5)$ & $83(6)$ & $62(5)$ & - & & \\
\hline Field: old (16) & $70(11)$ & $62(13)$ & $75(7)$ & $67(8)$ & $67(6)$ & $59(9)$ & $62(8)$ & $68(12)$ & $56(8)$ & $59(7)$ & - & \\
\hline Field (18) & $75(10)$ & $78(9)$ & $81(6)$ & $87(4)$ & $92(2)$ & $78(6)$ & $89(3)$ & $81(8)$ & $92(2)$ & $87(3)$ & $83(5)$ & - \\
\hline Shore meadow (13) & $68(11)$ & $71(10)$ & $72(7)$ & $68(7)$ & $60(6)$ & $53(9)$ & $47(9)$ & $69(11)$ & $47(8)$ & $76(4)$ & $62(8)$ & $93(2)$ \\
\hline
\end{tabular}


Figure 4 Species-area relationship (in loglog space) showing the differences in carabid species accumulations with the spatial configuration of the islands (group islands vs. scattered islands).

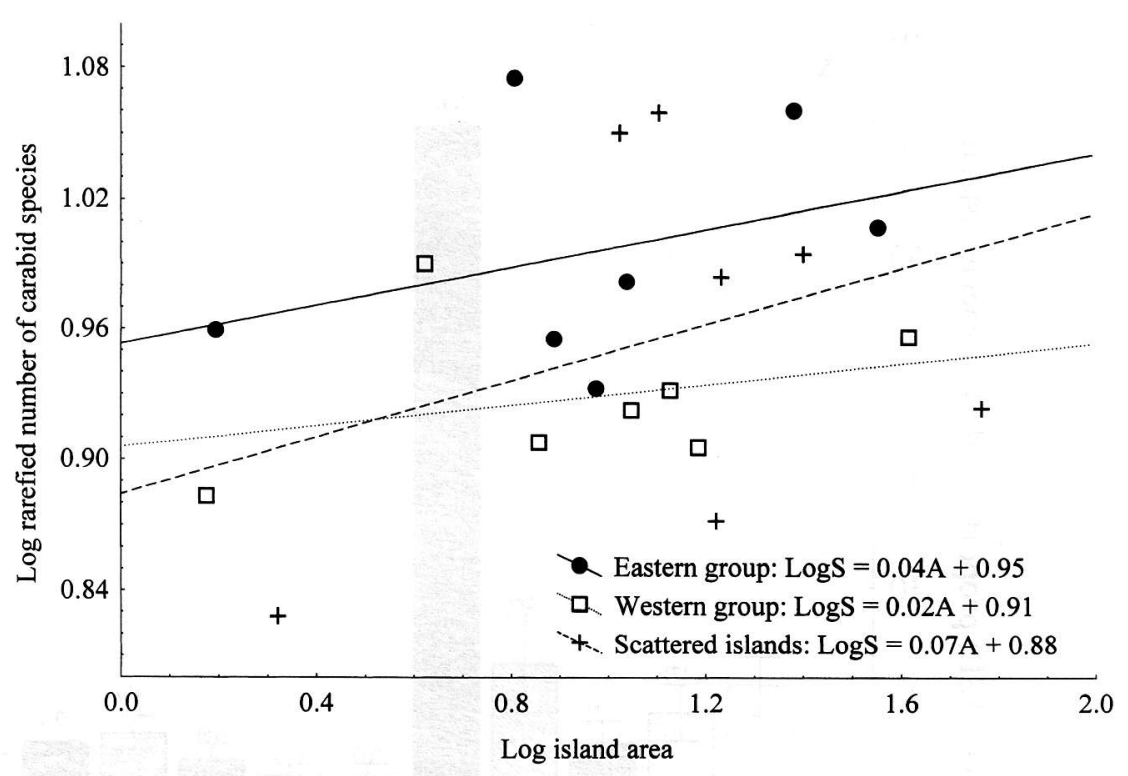

group islands showed a much higher mean proportion of individuals of brachypterous species (east, $7.5 \%$; west, $5.8 \%$ ) than the scattered islands.

Although the mean wing morph proportions changed little between islands, they were significantly different between mainland Finland and the islands. According to Lindroth (1985, 1986), 195 carabid species occur in the closest mainland area to the study site. If only macropterous and brachypterous species are considered (see Ås, 1984), the proportion of brachypterous species in the source area is 0.15 (24 species, Fig. 5A). The proportion of brachypterous species on the four island groups varied between 0.29 and 0.33 and, if all the islands are considered together, the proportion is 0.27 . This is significantly different from the mainland value $\left(\chi^{2}=10.65, P<0.005\right)$.

If dispersal was a limiting factor, we would expect to find more carabid occurrences on the group islands than on the scattered ones. However, carabid species with abundance $N \geq 10$ occurred equally frequently on scattered and group islands (Wilcoxon signed-rank test: $T=69.5, P=0.74$ ) (Fig. 6). Apart from the fact that only a few species captured on these island groups $(N \geq 10)$ were brachypterous, little inferences can be made concerning incidences of flying or non-flying species on these different island groups (Fig. 6). Nevertheless, scattered islands had a higher proportion of species represented by only three individuals or less $(21.8 \%)$, compared to the eastern $(17.8 \%)$ or western $(17.9 \%)$ group islands.

\section{DISCUSSION}

Unlike many of the world's oceanic islands which show a high rate of endemicity and have a low diversity in comparison to mainland fauna (Alcover et al., 1998; Chown et al., 1998), islands in the Baltic Sea have no endemic species and have comparatively high diversity (Ås et al., 1997). However, in terms of assemblage similarity to the mainland, carabids show considerable differences on islands (Ranta \& Ås, 1982; Niemelä et al., 1985). For instance, our study islands off the Finnish coast host a significantly higher proportion of wingless carabid species compared to their mainland counterparts. Ås (1984) found similar results studying carabids in the Stockholm archipelago. This has important implications for island theory.

Carabid species richness increased significantly with an increase in island area, but the slope of this relationship (0.06) was not as steep as commonly cited in the literature (MacArthur \& Wilson, 1967; Järvinen \& Ranta, 1987; Rosenzweig, 1995; Ås et al., 1997). An explanation for this discrepancy is that we did not sample all habitat types on the larger islands, and that these were undersampled. Larger areas have more habitat types, and the greater the habitat variety, the greater the species richness (Rosenzweig, 1995). Nevertheless, in this study (see Fig. 2B), as suggested by Ås et al. (1997) for Scandinavian archipelagos, habitat diversity might not be as important as area per se in explaining species richness on these islands. Also, excluding larger islands from the analysis did not change the slope of the relationship by much. If habitat diversity is not important $(z=0.02)$ and area only marginally so in explaining carabid species richness on these islands, what alternatives are there to explain the slow increase of species with island size? At least two points need consideration, one biological and the other physical.

First, carabids are mainly generalist, surface-active predators (Lövei \& Sunderland, 1996) and therefore not dependent on a specific vegetation type, although some species are restricted to certain habitat types. This was quite clear from our similarity analyses. For example, cluster analysis showed high similarity between the different forest types, while the two most commonly sampled habitat types on these islands, i.e. mixed forest and the juniper-heather-dominated scrub, shared many carabid species with most other habitat types. The only habitat types that showed a high degree of dissimilarity 

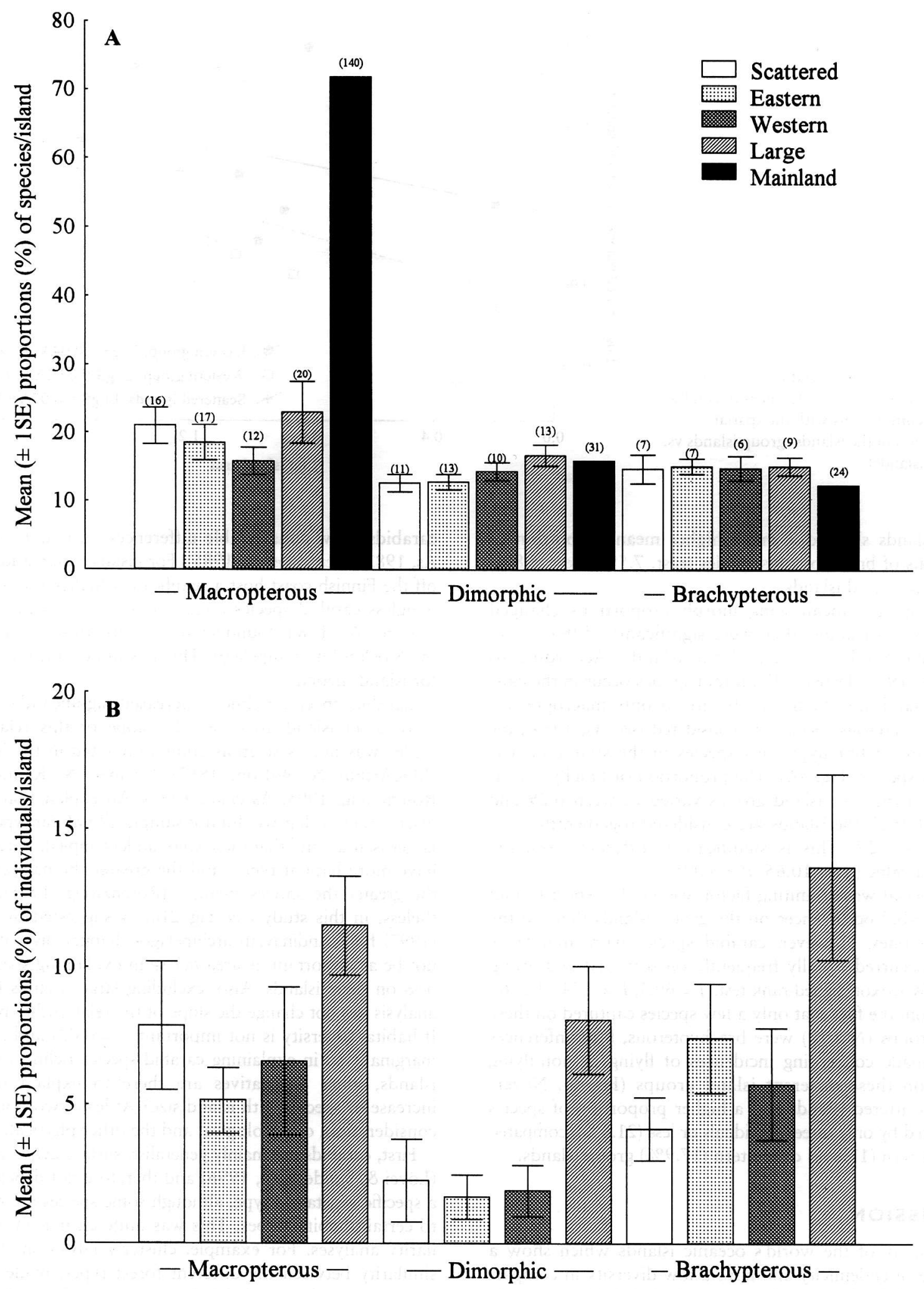

Figure 5 Mean $( \pm 1 \mathrm{SE})$ proportions of macropterous, dimorphic and brachypterous carabid species $(\mathrm{A})$ and individuals (B) encountered on the 24 islands sampled, and proportions of these wing morphs in the closest mainland area to the study site (Lindroth, 1985, 1986). Values above the bars are the total number of species per wing morph, per island configuration. Note that values do not add up to $100 \%$ as these are mean proportions. 
Figure 6 Numbers of occupied scattered islands against numbers of occupied group islands (eastern and western taken together). If more than one species is present per point position, it is so indicated. Open circles are macropterous and dimorphic species, while filled squares are brachypterous species.

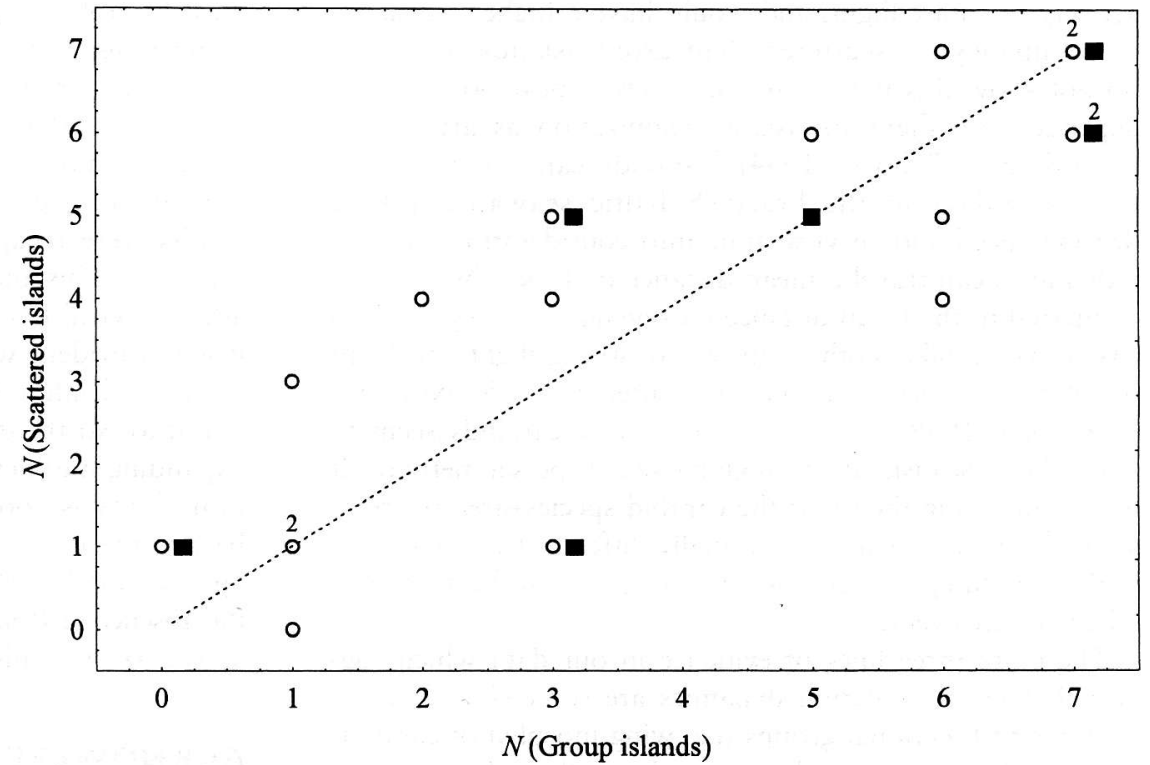

Wingless carabid species may have an adaptive advantage to winged species on these islands. Brachypterous individuals are presumably fitter, having energy allocated to increased fecundity or increased foraging efficiency rather than flight muscle development ( ̊s, 1984). Also, long-winged individuals stand an added risk of being blown off the windy islands (however, at the scale of this study, this may often lead to successful immigration to some other islands). For example, Clivina fossor and Loricera pilicornis were captured in low abundance on these islands, but are known to have welldeveloped abilities for flight and are often found abundantly in sea drift (Lindroth, 1985, 1986). These species, and other winged carabid species, may have a good dispersal potential, but may be less successful in colonizing new habitat. This is reflected by the higher mean proportion of individuals of macropterous than dimorphic or brachypterous species on the scattered islands (Fig. 5B). Also, between 17.8 and $21.8 \%$ of the carabid species captured on the island groups were represented by less than four individuals, suggesting that a high proportion of carabids on these islands have not yet established viable populations, or are unable to do so. Alternatively, it is well known that especially riparian species are good at flight (Niemelä, 1988a) but, as running waters of a suitable kind are probably lacking on the islands, these macropterous species are most likely to be unsuccessful colonizers. In summary then, dispersal between these islands appears to be easy, proportionally more so for wingless than winged carabid species.

Scattered islands accumulated carabid species only at a marginally faster rate than did group islands (compare $z$ values of Fig. 4), further supporting the idea that carabids colonize these islands with ease. Nieminen \& Hanski (1998) showed that, on Baltic skerries (with mostly non-breeding occurrences of moth species and strong fliers), the slope of the species-area relationship for moths was much steeper than on larger islands. They predicted that strong fliers can 
actively orientate flight, and would have a higher frequency of occupancy on scattered than group islands. Carabids do not show this pattern because they appear not to be as dependent on flight for island colonization as are moths. According to Palmén (1944), carabids can survive for at least 4-5 days in the brackish Baltic seawater. Taking drifting speed and survival time into consideration, carabid individuals can travel a mean distance of $13 \mathrm{~km}$ by floating, compared to the mean distance for one flight of only 3-6 km (Ås, 1984). Unlike moths then, where strong flight and flight orientation predict occurrence on scattered islands (Nieminen \& Hanski, 1998), a large proportion of carabids seem to reach Baltic Sea islands through passive dispersal methods. It is not surprising then that the carabid species-area relationships observed here are substantially different from that cited in the literature, because colonization appears to be a frequent albeit chance event.

There are three lines of evidence in our data which suggest that metapopulation dynamics are somewhat different in different functional groups (i.e. wing morphs) of carabids in the study area, as was the case in the moth study performed on the same islands (Nieminen \& Hanski, 1998). First, a larger mean proportion of individuals of macropterous species (compared to dimorphic and brachypterous species) was captured on scattered islands compared to group islands (Fig. 5B). This is an indication of their higher migration rate between islands, which was also found with moth species that are strong fliers (Nieminen \& Hanski, 1998). Second, the high migration rate of macropterous species also supports the prediction by Hanski \& Gyllenberg (1997) and Nieminen \& Hanski (1998) that scattered islands accumulate actively dispersing species quicker than islands close to each other (see Fig. 4). Third, based on Fig. 5B, it seems that, on group and large islands, there were relatively similar proportions of both macropterous and brachypterous individuals within each island category. However, these proportions are different on the scattered islands. We suggest that this is due to frequent successful migration among islands within island groups and among habitat patches on the large islands, which keeps the population sizes of brachypterous species larger there than on scattered islands (where migrating individuals are lost from the local population). For macropterous species, this pattern is reversed due to the above-mentioned accumulation effect on scattered islands and, as carabids fly on average $3-6 \mathrm{~km}$ (Ås, 1984), they leave the island groups very easily (Fig. 1).

In addition to dispersal ability, interspecific interactions (see Koivula et al., 1999) may explain at least one case of occurrence on the islands. Pterostichus niger was the most abundant species on the islands, while a closely related species $P$. melanarius was only found in low numbers on two large islands. A similar pattern has been found in the Åland archipelago west of our study islands, and Niemelä (1992) suggested that this might be due to interspecific competition between the two species. The mechanism may be a priority effect, whereby the somewhat larger $(15-20.5 \mathrm{~mm}) P$. niger might have been able to colonize the islands prior to the slightly smaller $(12-18 \mathrm{~mm})$ P. melanarius. The abundant $P$. niger may be able to prevent $P$. melanarius from establishing populations on the islands, although suitable habitat is available on the islands. P. melanarius is widely distributed on large islands (e.g. Åland) and occurs on them in similar habitats to those found on small islands. This species was introduced to one of our study islands where it did not occur before. Adults were recaptured 2 years later, but no recruits were recorded. This indicates that the habitat was suitable for adult survival but not for reproduction. On the other hand, it is not evident why $P$. melanarius should be a poorer disperser and inferior competitor. The species has been introduced to North America where it has been very successful in expanding into new areas. Thus, it appears that its colonization ability is good and there is no evidence that it would be an inferior competitor in North America (Niemelä \& Spence, 1991, 1999; Niemelä et al., 1997). In conclusion, the absence of $P$. melanarius from small Baltic islands remains a mystery and calls for experimental studies.

\section{ACKNOWLEDGMENTS}

We thank Illka Hanski for valuable comments on an earlier draft of the manuscript. Eero Halme is thanked for field assistance, while the Academy of Finland and the Finnish Biodiversity Research Programme (FIBRE) provided funding. Two anonymous referees provided constructive criticism.

\section{REFERENCES}

Alcover, J. A., Sans, A. \& Palmer, M. (1998) The extent of extinctions of mammals on islands. Journal of Biogeography, 25, 913-918.

Ås, S. (1984) To fly or not to fly? Colonization of Baltic islands by winged and wingless carabid beetles. Journal of Biogeography, 11, 413-426.

Ås, S., Bengtsson, J. \& Ebenhard, T. (1997) Archipelagoes and theories of insularity. Ecological Bulletin, 46, 88-116.

Baev, P. V. \& Penev, L. D. (1995) BIODIV; program for calculating biological diversity parameters, similarity, niche overlap, and cluster analysis, Version 5.1. Pensoft, Moscow.

Chown, S. L., Gremmen, N. J. M. \& Gaston, K. J. (1998) Ecological biogeography of southern ocean islands: speciesarea relationships, human impacts, and conservation. American Naturalist, 152, 562-575.

Colwell, R. K. \& Coddington, J. A. (1994) Estimating terrestrial biodiversity through extrapolation. Philosophical Transactions of the Royal Society of London, Series B, 345, 101-118.

Esseen, P.-A., Ehnström, B., Ericson, L. \& Sjöberg, K. (1997) Boreal forests. Ecological Bulletin, 46, 16-47.

Hanski, I. (1999) Metapopulation ecology. Oxford University Press, Oxford.

Hanski, I. \& Gyllenberg, M. (1997) Uniting two general patterns in the distribution of species. Science, 275, 397-400.

Järvinen, O. \& Ranta, E. (1987) Patterns and processes in species assemblages on Northern Baltic islands. Annales Zoologici Fennici, 24, 249-266.

Koivula, M., Punttila, P., Haila, Y. \& Niemelä, J. (1999) Leaf litter and the small-scale distribution of carabid beetles (Coleoptera, Carabidae) in boreal forest. Ecography, 22, 424-435. 
Lindroth, C. H. (1985) The Carabidae (Coleoptera) of Fennoscandia and Denmark. Fauna Entomologica Scandinavica, 15 (part 1). Scandinavian Science Press Ltd, Copenhagen.

Lindroth, C. H. (1986) The Carabidae (Coleoptera) of Fennoscandia and Denmark. Fauna Entomologica Scandinavica, 15 (part 2). Scandinavian Science Press Ltd, Copenhagen.

Lövei, G. L. \& Sunderland, K. D. (1996) Ecology and behavior of ground beetles (Coleoptera: Carabidae). Annual Review of Entomology, 41, 231-256.

MacArthur, R. H. \& Wilson, E. O. (1967) The theory of island biogeography. Princeton University Press, Princeton.

Magurran, A. E. (1988) Ecological diversity and its measurement. Princeton University Press, Princeton.

Niemelä, J. (1988a) Carabid beetles in shore-habitats on the Åland Islands, SW Finland: the effect of habitat availability and species characteristics. Acta Oecologica/Oecologia Generalis, 9, 379-395.

Niemelä, J. (1988b) Habitat occupancy of carabid beetles on small islands and the adjacent Alland mainland, SW Finland. Annales Zoologici Fennici, 25, 121-131.

Niemelä, J. (1992) Distribution of carabid beetles in the Åland archipelago, SW Finland (Coleoptera, Carabidae). The biogeography of Carabidae of mountains and islands (ed. by G. Noonan, G. Ball and N. Stork), pp. 175-186. Intercept Publications, Andover.

Niemelä, J. (1996) From systematics to conservationcarabidologists do it all. Annales Zoologici Fennici, 33, 1-4.

Niemelä, J., Haila, Y. \& Halme, E. (1988) Carabid beetles on isolated Baltic islands and on the adjacent Åland mainland: variation in colonization success. Annales Zoologici Fennici, $25,133-143$.

Niemelä, J., Haila, Y. \& Ranta, E. (1986) Spatial heterogeneity of carabid beetle dispersion in uniform forests on the Åland Islands, SW Finland. Annales Zoologici Fennici, 23, 289-296.

Niemelä, J., Haila, Y., Ranta, E., Tiainen, J., Vepsäläinen, K. \& Ås, S. (1987) Distribution of carabid beetles in four boreal archipelagoes. Annales Zoologici Fennici, 24, 89-100.

Niemelä, J., Ranta, E. \& Haila, Y. (1985) Carabid beetles in lush forest patches on the Åland Islands, south-west Finland: an island-mainland comparison. Journal of Biogeography, 12, 109-120.

Niemelä, J. \& Spence, J. R. (1991) Distribution and abundance of an exotic ground-beetle (Carabidae): a test of community impact. Oikos, 62, 351-359.

Niemelä, J. \& Spence, J. R. (1999) Dynamics of local expansion by an introduced species: Pterostichus melanarius Ill. (Coleoptera, Carabidae) in Alberta, Canada. Diversity and Distributions, 5, 121-127.
Niemelä, J., Spence, J. \& Cárcamo, H. (1997) Establishment and interactions of carabid populations: an experiment with native and introduced species. Ecography, 20, 643-652.

Nieminen, M. \& Hanski, I. (1998) Metapopulations of moths on islands: a test of two contrasting models. Journal of Animal Ecology, 67, 149-160.

Palmén, E. (1944) Die anemohydrochore Ausbreitung der Insekten als zoogeographischer Faktor. Annales Zoologici Societatis Zoologicae Botanicae Fennicae Vanamo, 10, 1-262.

Ranta, E. \& Ås, S. (1982) Non-random colonization of habitat islands by carabid beetles. Annales Zoologici Fennici, 19, 175-181.

Rosenzweig, M. L. (1995) Species diversity in space and time. Cambridge University Press, Cambridge.

Saccheri, I., Kuussaari, M., Kankare, M., Vikman, P., Fortelius, W. \& Hanski, I. (1998) Inbreeding and extinction in a butterfly metapopulation. Nature, 392, 491-494.

Simberloff, D. S. (1978) Use of rarefaction and related methods in ecology. Biological data in water pollution assessment: quantitative and statistical analysis (ed. by K. L. Dickson, J. Garins, Jr and R. J. Livingston), pp. 150-165. American Society for Testing and Materials, STP 652, Philadelphia, PA.

Spence, J. R. \& Niemelä, J. K. (1994) Sampling carabid assemblages with pitfall traps: the madness and the method. Canadian Entomologist, 126, 881-894.

Wu, J. \& Vankat, J. L. (1995) Island biogeography, theory and applications. Encyclopedia of environmental biology 2 (F-N) (ed. by W. A. Nierenberg), pp. 371-379. Academic Press, San Diego.

\section{BIOSKETCHES}

Johan Kotze is a postdoctoral scientist, teaching and working in the Department of Ecology and Systematics at the University of Helsinki, Finland. For the last 2 years, he has been mainly working on carabid beetles on islands and in urban environments.

Professor Jari Niemelä teaches in the Department of Ecology and Systematics at the University of Helsinki, Finland. His research interests include island biogeography and carabid beetles.

Dr Marko Nieminen works as a researcher in the Division of Population Biology of the Department of Ecology and Systematics at the University of Helsinki, Finland. His interests focus on metapopulation biology. 
H $000000-000000000-0$ h hoo

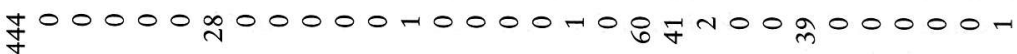
T00000m-00000000H00 hy H.

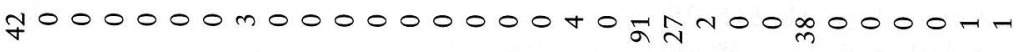
t $1000000-0000000000000 \pi 00-000000$ $+000004-0000000000000000000000$ 6000000000000000000070000000000

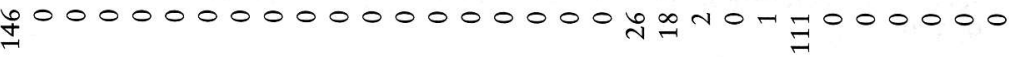
I $00000 \mathrm{mn} 00000000000 \mathrm{~m} 30007000000$ $0000000000000000000 \frac{1}{10}+00 \pi 000000$ $0000007-000000000404 \pi 400$ nु 000000 $000000040000000000400 n 0070 h 4000$ $000000-000000000000 \mathrm{~h}^{0 N 00 N 000000}$

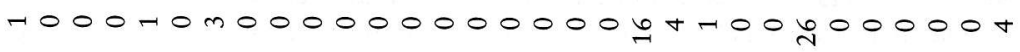

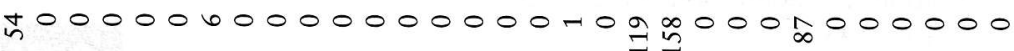

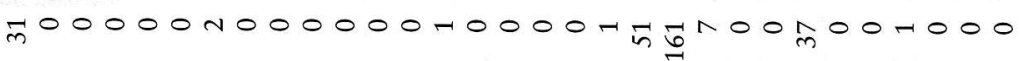

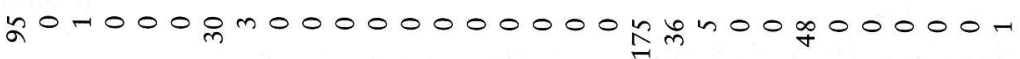

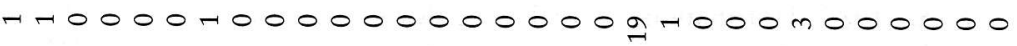
$100000 \mathrm{gm} 00000000000$ j్

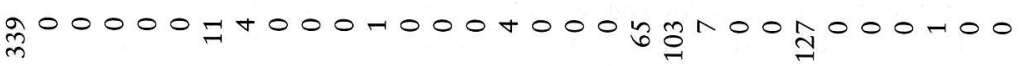

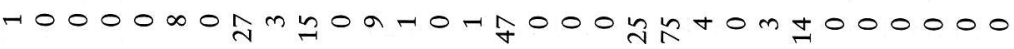
N00-000-0000000-0-0000-00000000

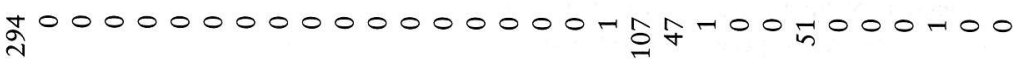

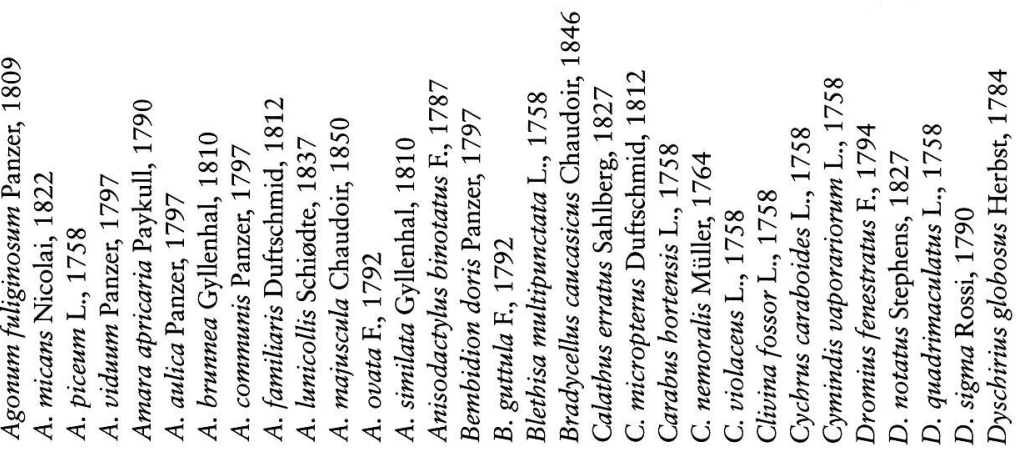




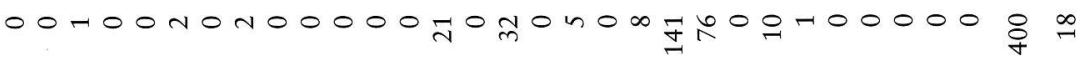

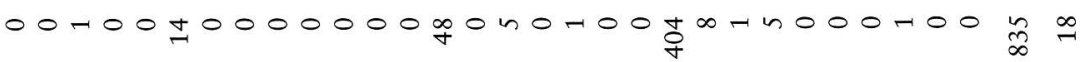

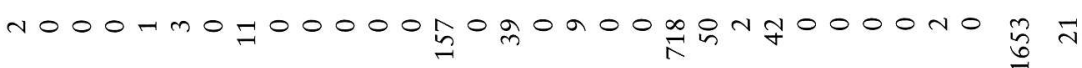

$$
\begin{aligned}
& 0000-00-0000 m 0000000 \text { न }
\end{aligned}
$$

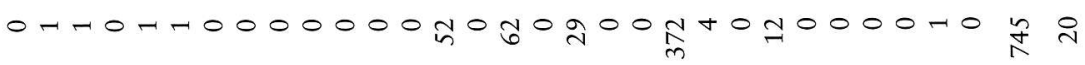

$$
\begin{aligned}
& 00000 m 00000000000=00 \ln _{0} 0 m_{0} 00000 \text { I }
\end{aligned}
$$

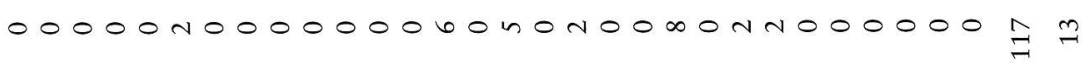

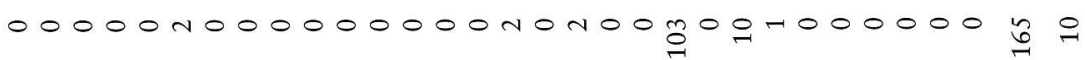

$$
\begin{aligned}
& 00000-000000000 \mathrm{~m} 0 \mathrm{H} 00 \mathrm{~m} m 0-000000 \mathrm{~m} \text { I }
\end{aligned}
$$

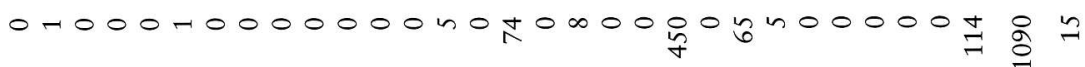

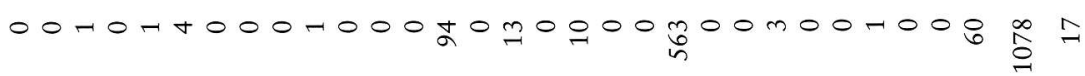

$$
\begin{aligned}
& 0000-700-m 0-00000 \mathrm{mon} 000000000 \mathrm{n} \text { I } \\
& 0-000 \mathrm{H} 00000000000-000000000000 \stackrel{m}{=} \\
& 000000000000000 n 0 m 00700-1000000 \text { 而 }
\end{aligned}
$$

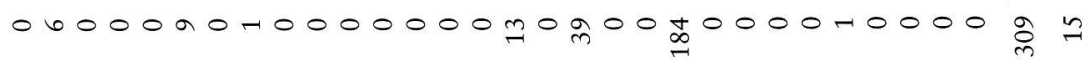

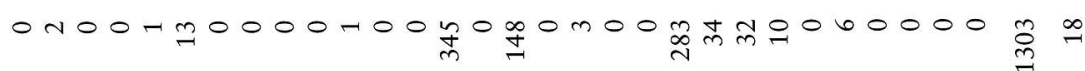

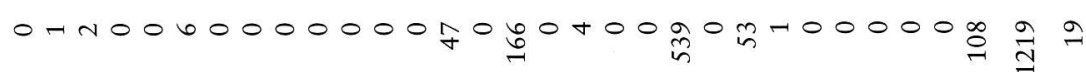

$$
\begin{aligned}
& 0000-000000-0-0 \text { m } \\
& 00000000000-000 m 0 N 00 m 0-0000000 \text { i h }
\end{aligned}
$$

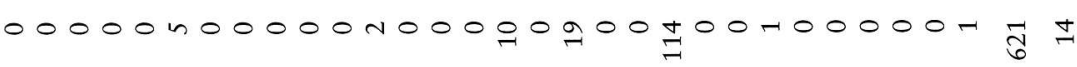

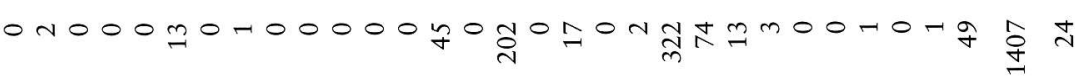

$$
\begin{aligned}
& \text { omnhoto }
\end{aligned}
$$

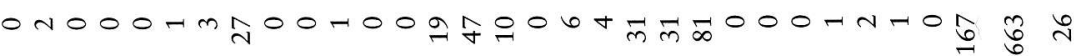

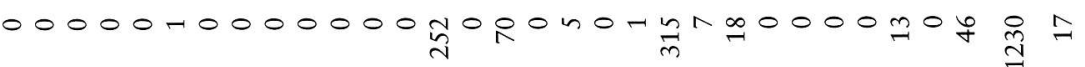

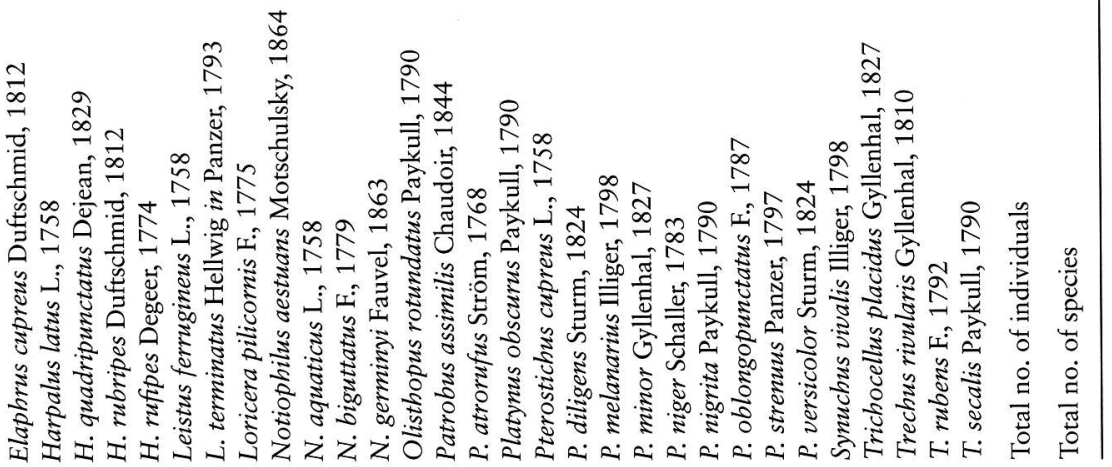

